\title{
Postmodernizm Ardalanında Halkla İlişkilerin Aktivist Rolüne Yönelik Bir Arayış
}

DOI: 10.26466/opus.522169

\section{Asli İcil Tuncer $^{*}$}

${ }^{*}$ Dr. Öğr. Üyesi, Aydın Adnan Menderes Üniversitesi İletişim Fakültesi Aydın/Türkiye E-Posta: atuncer@adu.edu.tr

ORCID: 0000-0003-3171-4682

Öz

Postmodern dünyada halkla ilişkilerin aktivist rolünün arayışındaki bu çalışma, farklılıkları keşfederek cllız seslere gü̈ç veren ve değişimin ajanı olan halkla ilişkilerin izini aramaktadır. Postmodernizm, halkla ilişkilere farklılıklar, karşıtlıklar yoluyla yeni anlamları üretebileceği bir zemin sunar. Bu zeminde halkla ilişkiler, işlevselci bir yaklaşımla ortaya konan amaçlara ve uygulamalara -ki bunlar büyük ölçüde örgüt merkezli bir yaklaşımı temsil eder- meydan okur. Bu araştırmada katılımcıların bakış açıları, Q-örneklemede sistematik sıralar ile modellenmeye çalışılmıştır. Elde edilen veriler PQMethod 2.35 programı ile analiz edilmiştir. BIST Kurumsal Yönetim Endeksi'ne dahil olan 20 örgütün halkla ilişkiler uygulayıcıları araştırmaya dahil edilmiştir. Örgüt yönlü kararlar, halkla ilişkiler uygulayıcılarının aktivist rolünün varlığına ilişkin şüpheli bir bakışa neden olmuştur. Zira uygulayıcıların toplumla ilişki kurarken örgütün politikaların takip etmesi ve kamuları örgütün kararlarına ikna etmedeki rolleri, değişim arayışı ve zayıf sesleri güçlendirme ile aynı yerde işleyemez. Halkla ilişkilerin aktivist rolüne ilişkin arayış bu araştırmanın sonuçlarına bağhı olarak şimdilik bir beklenti olarak durmaktadır. Yine de zayıf da olsa kanıtların varlı̆̆̆ aktivist bir halkla ilişkiler için başlangıç noktası olarak sayılabilir.

Anahtar Kelimeler: Aktivizm, halkla ilişkiler, uygulayıcı rolleri

OPUS (c) Uluslararası Toplum Araştırmaları Dergisi-International Journal of Society Researches ISSN:2528-9527 E-ISSN : 2528-9535

http://opusjournal.net 


\title{
A Search For The Role of Public Relations Activist in The Background of Postmodernizim
}

\begin{abstract}
In the postmodern world, this study in the search for the activist role of public relations seeks to trace the differences in public relations, an agent of change, that explores differences and strengths the weak sounds. Postmodernism offers a ground where it can produce new meanings through differences and oppositions. Public relations on this ground challenge the goals and practices set out in a functionalist approach, which represent a largely organizational-centered approach. In this study, the perspectives of the participants were tried to be modeled with $Q$-sampling systematically. The data were analyzed with PQMethod 2.35. Public relations practitioners of 20 organizations included in BIST Corporate Governance Index were included in the study. Organizational directives have led to a suspicious view of the existence of the activist role of public relations practitioners. Because, it is not possible for practitioners to follow the policies of the organization when establishing a relationship with the society and the role of persuading the public in convincing the decisions of the organization, searching for change and strengthening the weak voices. The search for the activist role of public relations remains an expectation due to the results of this research. Nevertheless, the presence of evidence may be considered as a starting point for an activist public relations.
\end{abstract}

Keywords: Activism, public relations, practitioner roles 


\section{Giriş}

Örgütlerin gücüne meydan okuyan aktivistlere karşı halkla ilişkilerin tarihsel bir düşmanlığ vardır (Holtzhausen, 2011). Lakin ironik bir biçimde halkla ilişkiler araçlarının çoğunu geliştiren ve kullananlar da yine aktivistlerdir (Coombs ve Holladay, 2007, s. 52). Bu gruplar işlevselci bir yaklaşımla dış kamular olarak görülmüştür. Grunig ve Grunig'in (1989, s.32) "aktif halkların üyeleri aktivist gruplara katıldıklarında, halkla ilişkiler problemi yaratan ve halkla ilişkiler programı ihtiyacını ortaya çıkaran örgütsel özerklik üzerindeki baskılara katkıda bulunurlar" diyerek hatırlattığı gibi, işlevsel yaklaşımlar içinde, aktivistler örgütlerin aşması gereken "engeller" dir. Ancak, halkla ilişkiler toplumsal gerçeği şekillendirebilecek güce sahip sosyo-kültürel bir eylemdir (Edwards ve Hodges, 2011). Bu eylem postmodern bir bakışla, farklılıkları ve cılız sesleri karşı gruplar olarak işaret etmek yerine, gruplara ses vermeyi, muhalif fikirlerden beslenmeyi ve nihayetinde halkla ilişkilerin örgüt ve toplumu dönüştürmedeki gücünü açıklayabilir. Postmodern bakış, süregelen modernist anlayıştan ziyade, halkla ilişkilerin ne olduğuna ilişkin başka bir cephe açmak demektir. Bu cephe halkla ilişkilerin, toplum üzerindeki etkileri dar anlamda tanımlanmış bir örgütsel işlev yerine, daha geniş bir sosyal, kültürel ve politik bağlamda anlaşılmasına katkı sağlayabilir (Holtzhausen, 2000). Postmodern dünyada halkla ilişkilerin aktivist rolünün arayışındaki bu çalışma, farklılıkların keşfederek cılız seslere güç veren ve değişimin ajanı olarak halkla ilişkilerin izini aramaktadır. Halkla ilişkilerin kendini örgütsel değerlerin dişında tutarak bir yeni bir anlam inşa edebileceği normatif bir beklenti de olabilir. Yine de, makro güce direnme gücüne sahip olan bilinçli katılımcı olarak bireye odaklanan Foucault'nun (1988, s.118) deyişiyle "bir güç ilişkisi olduğu anda, bir direnme olasılığı vardır".

\section{Postmodern Bir Halkla İlişkiler}

Halkla ilişkiler literatürü, yönetim ve iletişim kavramına odaklanan, örgütsel etkinliği vurgulayarak stratejik yönetimin bir parçası olarak halkla ilişkilere değer biçen tanımlarla doludur. Bu tanımlamalarda halkla ilişkilerden, bir örgütle paydaşları ve kamuları arasındaki iletişimi yöneten bir işlev (Grunig ve Hunt, 1984) ve bir örgüt ve örgütün başarısına etki eden 
kamuları arasındaki karşılıklı yararlı ilişkiler kuran ve sürdüren bir yönetim fonksiyonu (Cutlip, Center ve Broom, 2000) olarak söz edilmektedir. Zira yirminci yüzyılın başlarında modernizme paralel olarak halkla ilişkiler de kaçınılmaz olarak modern düşünce ile şekillenmiştir. Lakin Wehmeier'ın da (2006) eleştirdiği gibi işlevselci ve pozitivist yaklaşımlar, halkla ilişkilerin planll, kontrollü ve çoğunlukla proaktif olarak tasarlanmış "iletişim"le ilgilendiğini varsaymaktadır.

Postmodern bir yönle halkla ilişkileri tanımlamaya, postmodernizmin temel argümanlarını açıklayarak başlamak gereklidir. Postmodernizimi, modernizmin devamı olarak açıklayan Habermas'ın (1997) aksine Lyotard $(1990,1991)$ için postmodernizim, modernizim sonrası oluşan topluma ait bir "durumdur". Postmodern durum, öncekileri yeni bir ışık altında yeniden düşünmek anlamında bir yeniden okumadır. Postmodernizm, modernist yaklaşım dâhil olmak üzere birçok farklı fikri ve yaklaşımı barındırır. Bu nedenle, popüler inancın aksine, postmodernizm modernizmin yerini almayı değil, yalnızca merkezciliğini egemen söylem olarak yerinden etmeyi amaçlamaktadır (Holtzhauzen, 2000). Lyotard'in $(1984,1989)$ fikirleri postmodern bir halkla ilişkileri tanımlamaya yarayacak şekilde okunabilir. Postmodernizm, bir "doğru" fikir veya "gerçek hikâyeyi" anlatan bir büyük anlatı (Lyotard, 1984, 1990) yerine çok sayıda fikri desteklemektedir. Lyotard (1990) buluşların ve yeni düşünme ve çözme yollarının, uzlaşma yerine karşıtlıklardan doğduğuna inanır. Karşıt sesler yani "tensörler"deki (çelişki noktaları), fikir ayrılıkları düşünmeyi genişletir. Aksi haldeki fikir birliği düşüncenin sonunu getirmektedir. Dahası, Lyotard gibi Foucault'un (1984, s.9) izdüşümü takip edilirse, halkla ilişkiler "bilineni meşrulaştırmak yerine, farklı düşünmenin nasıl ve ne ölçüde mümkün olabileceğini” gösterebilir. Uygulayıcılar, farklılık ve muhalefet yoluyla anlamın üretildiği yeni koşulları geliştirebilir ve yaratabilirler. Zira halkla ilişkiler uygulayıcıları, söylemin muhafaza edilmesine ve dönüşümüne metinlerin üretilmesi ve dağıtılması yoluyla katılırlar (Motion ve Leitch, 1996, s. 298-299). Nihayetinde halkla ilişkiler metinleri şekillendirme gücünü, zıtlıkları ve farklılıkları yaratıcı bir kaynak olarak kullanarak gösterebilir. Zıtlıklar ve farklılıkları açığa çıkarmak, desteklemek ve bu fikirlerin dolaşımını sağlamak Bourdieu (1986, as cited Ihlen, 2007) izinden bir okumayla halkla ilişkilerin sosyal sermayeye katkı sağlamasının bir yolu olarak da tartışılabilir. Sosyal sermaye, insanlar ve 
gruplar arasındaki ilişkilerde bulunur ve sosyal etkileşimlerle çoğalır. Öyle ki, halkla ilişkilerin de tarihsel işlevi, sosyal gruplar ve ağlar arasında bilgi oluşturmak ve paylaşmaktır (Zhang ve Abitbol, 2016; Yang ve Taylor, 2013; Sommerfeldt ve Taylor, 2011; Ihlen, 2005, 2007). Bilgiler ve bağlantıların paylaşılması sermaye transferini ortaya çıkarır ve sosyal sermeyenin değerini somutlaştırır. Nihayetinde sosyal sermaye açıkça sosyaldir, Putnam'ın (2000) güçlü sivil bağlantılar olarak adlandırdığı bireyler ve örgütler arasındaki ilişkilerde bulunur. Kruckeberg ve Starck (1988) da kaotik bir ortamda, örgütün üye olduğu toplumun bir parçası olarak sosyal ilişkilerin çok sayıda farklılıkla dolu olduğunu kabul etmesi gerektiğinden söz etmektedir. Dolayısıyla postmodern bakış açısı, halkla ilişkilerde "ilişkilerin" değerini açı̆̆a çıkaran bir yaklaşımdır. İlişkileri diyoloğa dayalı karşılaşmaların sonucu olan ve yaşayan olaylar olarak görerek, deneyimleri standartlaştırmak yerine farklı seslere kulak verebilmek için çıkış noktaları sunar.

Postmodern bir halkla ilişkilerden söz ediyorsak, ilişkiler değerlidir fakat bu ilişkiler modernist bir bakıştan farklı biçimde tanımlanmalıdır. Öyle ki modernist örgütlerde halkla ilişkiler örgütün ilişkide olduğu grupları kamular ve paydaşlar olarak açıklar. İşlevselci yaklaşımla, kamu terimi bazı ortak çıkar ya da sonuçlar için birbiri ile ve örgüt ile bağları olan bir grup insanı kapsamaktadır. Kamu dışı gruplar (Dozier, Grunig, ve Grunig, 1995, s. 32) örgütten etkilenen ancak farkındalığ1 düşük gruplardır. Buna ek olarak paydaşlar, daha geniş gruplara çağrı yapar ve örgütün hedeflerinin gerçekleşmesinden etkilenen ya da bu hedefleri etkileyebilecek olan grupları (Freeman, 1983) anlatır. Ama burada, postmodernizmin çok sesli, çok kültürlü ve parçalanmış dünyasında, Kruckeberg ve Vujnovic'in (2010, s.110) 21.yüzyılda herhangi bir kesinlik ile tanımlanabilecek tek gerçek stratejik halkın genel kamuoyu olduğu varsayımına kulak vermek faydalı olabilir. Bu varsayım, Kruckeberg (2006) organik halkla ilişkiler olarak açıkladığı bir yaklaşıma dayanır. Küresel ve postmodern bir toplumun karmaşıklığına yanıt verecek bir halkla ilişkiler organik olmalı, yani örgütleri sosyal düzenin sadece bir parçası olarak, merkezde açıklamamalıdır. Dolayısıyla örgüt toplumu, örgüt için endişe kaynağ olarak tanımlanan stratejik kamular olarak değil, daha geniş bir sosyal sistem olarak görmeli (Vujnovic, 2005) ve tüm topluma karşı sorumluluğunu kabul etmelidir (Kruckeberg ve Vujnovic, 2006; Kruckeberg ve Vujnovic, 
2010). Postmodernizimin çok kültürlülüğü, sayısız küresel topluluğu açığa çıkarması bunun nedenlerinden biri olarak açıklanabilir. Yeniden üretmeye ve/veya dönüştürmeye hizmet eden toplumdaki iletişimsel güçtür. Dolayısıyla özgürleşme ve dönüşümün yeniden üretimini sağlayabilen bir meslek olarak halkla ilişkilere değer biçilmelidir.

\section{Halkla İlişkiler Uygulayıcısının Aktivist Rolü}

Halkla ilişkiler postmodern bir yaklaşımla açıklandığında, planlama, düzenleme, kontrol etme ve yeniden düzenleme işleviyle örgütün baskın ideolojisini yaymaktan daha başka bir rolle tanımlanmaya ihtiyaç duymaktadır. Halkla ilişkiler uygulayıcılarının rollerini sınıflandıran çok sayıda çalışma, (Dozier ve Broom, 1995; Dozier, 1984; Broom, 1982; Broom ve Smith, 1979) teknisyen ve yönetici rollerinden sıklıkla söz eder. Bu rollerde uygulayıcıların örgüt siperlerine yaptığ 1 "yardım” örgütsel etkinliğe katkı bağlamıyla sunulmaktadır. Teknisyen rolüyle uygulayıcılar rutin programlar üretip yayma eğilimindedir; yöneticiler programların ne olacağı ile ilgili kararlarda aktiftir. Yönetici rolünde ise uygulayıcıların örgütün karar masasında yer alması ve uygulamadaki araçları belirlemedeki özerkliği tartışılmaktadır. Yönetici rolünde uygulayıcının başarısı karar masasındaki etkisine ve örgütün stratejik hedeflere katkı sağlayıp sağlamadığı ile belirlenmektedir. Deetz (2001, s. 35) "etkinlik", "uzman" ve "stratejik mesajlar" terminolojisinin kontrol sistemlerini meşrulaştırmak için kullanıldığından söz eder. Bowen' in (2007) fikirleri daha da keskindir; halkla ilişkiler, demokratik sürece zarar verir: kazanılmış hakları belirsizleştirir, aldatır, toplumsal faydayı yok eder. Eleştirilerde halkla ilişkilerin sadece örgütün sesi olması, doğasında vardır. Tuncer (2018, s.11) için de geleneksel olarak sadece tanıtma amacı taşıyan tek boyutlu halkla ilişkiler tarihi genellikle iknaya dayanan ve asimetrik uygulamaları karşımıza çıkarır. Ancak halkla ilişkilerin salt yönetim işlevi olarak tanımlanması, örgütsel düzeyde halkla ilişkilere miyop bir odak ile bakmak demektir (Curtin ve Gaither, 2005, s. 94). Aksine halkla ilişkilerin makro ve meso düzeylerde sosyal değeri görünürdür ve örgütte güç-kırıcı bir aktivist rol üstlenen bir güç olarak çözümlenebilir. 
Aktivist rol, hem üretim ve hem de tüketim alanlarında varolan uygulayıcıları, değişimin ajanı olarak vurgular, bilginin şekillendirilmesi ve aktarılması yoluyla anlam yaratmak için yeniden konumlandırır. Bu bakışla halkla ilişkiler örgütün vicdanına hizmet eder ve kamuların örgütle olan ilişkisinde güçsüz olanlara ses verebilir. Nihayetinde halkla ilişkiler, farklı sesleri dinler ve muhalefet yoluyla yeni anlamın üretildiği koşulları yaratabilir ve geliştirebilir. Öyle ki, halkla ilişkilerin farklı seslere yansıtmadaki gücü, halkla ilişkilerin örgütte varolma sebebinin sosyal sorumluluk olduğuna ilişkin fikirlerden (Grunig ve Hunt, 1984, s. 48) bir adım öteye varmaktadır. Molleda ve Ferguson (2004) açıkladığı sosyal roller belki de halkla ilişkiler uygulayıcılarının sosyal değişime aracı olabileceğine ilişkin kanıtlar gösterebilir. Diğer yandan Grunig ve White'1n (1992, s. 52-53) radikal ve idealist toplumsal rolü, postmodernizm ardalanında açılanan halkla ilişkilerde, uygulayıcıların rollerine ilişkin fikirler verebilir. Zira yazarların açıkladığı gibi, radikal bir rolle halkla ilişkiler uygulayıcısı, toplumsal ilerlemenin, reformun ve değişimin önünü açar. İdealist rol, radikal rolün bir tamamlayıcısı gibidir; halkla ilişkiler kamu yararına hizmet eder, toplumdaki konular hakkında bilinçli tartışmaya katkıda bulunur ve örgütler ile toplumlar arasındaki diyaloğu kolaylaştırır. Toplumsal sorunların çözümüne ilişkin öneriler geliştirmek sorumluluklarının bir parçasıdır. Han (2002) da uygulayıcıların idealist rolüne ilişkin izler bulmuştur. İdealist, sosyal ve radikal roller bu çalışmada aktivist rol çatısıyla açıklanmaktadır. Zira üç rol tipolojiside toplumsal bağlam üzerine kuruludur. Meso ve makro sosyal seviyede halkla ilişkiler için toplumsal bağlam önemlidir (Verhoeven vd. 2018).

Postmodernizmin uzlaşmanın yerine fikir ayrılığını (dissensus) koyması, uygulayıcının rolünü uzlaşma için çabalamaktan ziyade, örgüt ve toplum arasındaki tensörleri tanımlamaya dönüştürür. Uzlaşma halkla ilişkiler literatüründe simetri olarak varsayılmaktadır (Dozier, Grunig ve Grunig, 1995; Pearson, 1992). Kennedy ve Sommerfeldt'in (2015) fikirleri, halkla ilişkiler alanı için neden uzlaşma yerine farklılıklara odaklanmak gerektiğine ilişkin bir yön sunar. Simetri uzlaşma ve sistem dengesi üzerinde durur, bu da farklıkların zamanla kaybına neden olur. Aksine, Lyotard (1991) uzlaşma yerine farklılık ve bölünmeyi önermektedir. Mutlak bir uzlaşma yerine zamansal ve yerel çözümler aranmalıdır. İşte tam da bu noktada, hem asimetrik hem de simetrik uygulamaları içeren karma 
motifin kullanımına ilişkin veriler (Dozier, Grunig ve Grunig, 1995) Lyotard'ın aslında gerçek uzlaşmanın imkansız olduğu iddialarını destekler gibidir (Holtzhauzen 2000, s. 108). Gerçek uzlaşma imkansızsa, halkla ilişkiler çelişki noktalarından hareket alarak, farklılıklara odaklanabilir. Postmodern halkla ilişkiler pratiğini örgütsel bir aktivist olarak açıklamak cazip gelse de, oldukça idealist bir fikir de olabileceği yadsınmamalıdır. Tüm bunlara rağmen, örgütlerin daha güçlü ve baskın sesi, toplumdaki marjinalleştirilmiş seslerin üstesinden gelme potansiyeline sahip olabileceği hatırda kalmalıdır. Böyle bir durumda, sınır aşıcı uygulayıcı, postmodern bir örgütsel aktivistin rolünü harekete geçirmek için muazzam fırsatlar ile karşı karşıyadır. Ancak örgütün ve çoklu grupların çıkarlarını eşzamanlı olarak temsil etmek muazzam zorluklar barındırmaktadır (Dhanesh, 2013, s.399).

\section{Amaç}

Halkla ilişkiler alanı uzun yıllardır, zayıf etik ve şüpheli uygulamalar yüzünden eleştirilmiştir. Döngü doktoru ve rıza mühendisi gibi terimler, halkla ilişkiler uygulayıcılarının etik ve güvenilirliğine meydan okuyanların cephaneliğinin bir parçası haline gelmiştir (Houlthauzen ve Voto, 2002). Postmodern bir bakış, toplumsal değerlerin yaratılmasını ve dönüştürülmesini, örgütün vicdanı olarak hizmet etmeyi ve iktidar olmayanlara ses verilmesini sağlayabilir. Holtzhausen (2000) halkla ilişkilerin aktivist rolüyle örgütlerde eylemci bir tutum sergilemesi halinde halkla ilişkiler pratiğinin daha etik olabileceğini savunurken halkla ilişkilerin "toplumlarda demokrasiye ve özgürlüğe katkısını, yıkarak ya da inşa ederek değil, içinde çalışarak, özgürleştirici olarak sağlayabileceğinden" söz eder (s.110). Postmodernizmi ardalanına alan bu araştırma, halkla ilişkilerin aktivist rolünün varlığına ilişkin kanıtlar bulmanın peşindedir. Nihayetinde postmodern bir mercekle uygulayıcı davranışına bakmanın halkla ilişkilere mezo ve makro seviyede farklı bir anlayış sağlayacağını savunmaktadır. Bu argümanlarla çalışma şu soruyu sormaktadır: Halkla ilişkiler uygulayıcıları örgütlerde aktivist bir rol üstlenmekte midir? 


\section{Yöntem}

$\mathrm{Bu}$ araştırmada halkla ilişkiler uygulayıcılarının aktivist rollerine ilişkin kanıtlar, $Q$ yöntemi ile aranmıştır. $Q$, katılımcıların çok sayıda yargı içinden kendilerini en çok ifade edenden en aza bir sıralama yaptıkları yöntemin adıdır. Yöntemde bireyin öznelliğine (kişisel bakış açısı, tutumları ve inançları) odaklanılır (Brown, 1986). Yöntemin üç bileşeni vardır: Puanların atılacağı tanımlayıcı maddelerin setlerinin geliştirilmesi; madde setlerine puanların atılması ve verilerin analizi. (Waters ve Deane, 1985, s. 52). $\mathrm{Q}$ araştırmacıları, her bir konu için değişkenler arasında bir desen aramaktadır. Katılımcıların bakış açıları, Q-örnekleme (McKeown ve Thomas, 1988) olarak adlandırılan sistematik sıralar ile modellenmeye çalışılır. Araştırmada Q-dizgisinde, -4 negatif uç ile +4 pozitif uç arasında, zorunlu normal dağılım yapısı kullanılmıştır. Katılımcıların her birine önceden kartlara yazılmış madde setleri ve 70X100 boyutunda bir alanda Q-dizgisi verilmiştir. Katılımcılardan kendilerine karışık halde verilen fikir kartlarından tamamen desteklediklerini Q-dizgisindeki +4 kısmına; hiç desteklemedikleri fikir kartlarını ise -4 kısmına ve fikirlerinin olmadığ ise 0 (nötr) bölümüne yerleştirmeleri istenmiştir. Diğer ifadeler +3 ve -3 aralığında derecelendirilmiştir. Q-setindeki boyutlar ve ifadeler Molleda ve Ferguson (2004), Kim ve Kim (2009) Holtzhausen ve Voto'dan (2002) derlenerek oluşturulmuştur.

Edilen veriler PQMethod 2.35 (Schmolck, 2014) programı ile analiz edilmiştir. Program ile Q-sırasının bir korelasyon matrisi hesaplanmış ve faktör bileşen analizi kullanılarak faktör analizi yapılmıştır. Q-dizgisinin yapısını vurgulamak için varimax rotasyonu (Kaiser, 1958) kullanılmıştır. Nihayetinde katılımcıların bir faktöre yükledikleri oran arttıkça, bu faktörle temsil edilen bakış açısı da ortaklanmıştır (McKeown ve Thomas, 1988). Dört faktör 29 ayrı Q-türü arasındaki varyansın \% 59'unu açıklamaktadır.

\section{Araştırma Modeli}

Pavlik (1987 as cited in Sha, 2001) halkla ilişkiler alanındaki en eski sistematik analizlerden birinde, üç araştırma alanı belirlemiştir: (a) bir teorik 
bilgi sistemi oluşturmak için yapılan temel araştırmalar, (b) Halkla ilişkiler programlarının tasarımı ve yürütülmesini iyileştirmek için yapılan araştırmalar ve (c) alanın kendisi hakkında "iç gözlem" araştırması. Bu araştırma Pavlik (1987) tanımladığı iç gözlem araştırmalarındandır.

\section{Evren ve Örneklem}

Halkla ilişkilerin aktivist rolü, örgütlerdeki halkla ilişkiler uygulayıcıları üzerinden değerlendirilmiştir. Uygulayıcıların rollerini açıklamak, halkla ilişkilerin işlevini de anlamayı sağlayabilir (Dozier, 1984). Modernist yapılarda postmodern dünyaya ait bir role ilişkin izler aramak tartışmalı gibi görünebilir. Ancak halkla ilişkiler doğası gereği, örgütlü yapılarda varolmaktadır. Aktivist role ilişkin izler, BİST Kurumsal Yönetim Endeksi'nde yer alanlar örgütlerde varolabilir. Zira bu örgütler, OECD'nin 2004 yılında yayınladığ "Kurumsal Yönetim İlkeleri"ne uymakla yükümlüdür. Bu ilkelerin bu araştırma için değeri, diğer örgütlerden farklı olarak bu örgütlerin kurumsal vatandaşlık tanımlarında vurgulanan prensiplerin içselleștirilmiş olmasıdır. Dolayısıyla bu örgütlerde kurumsal vatandaşlık, karar alımına katılmada ve uygulayıcının rollerinde etik, șeffaf, hesap verebilirlik daha net görünebilir (Tuncer, 2015). Bu anlamda halkla ilişkilerin sosyal, kültürel ve politik bağlamlarının anlaşılması ve ilişkilerin değeri bu örgütlerden daha zengin verinin toplanabileceğini düşündürmüştür.

Araştırmaya 2018 yılı verilerine göre BİST Kurumsal Yönetim Endeksi'nde bulunan 51 örgüt (http://www.tkyd.org) dahil edilmiştir. Bu örgütlerin halkla ilişkiler uygulayıcılarına e-posta yoluyla ulaşılmış, yüzyüze görüşmeyi kabul eden 4 uygulayıcı ile yüzyüze görüşmeler gerçekleştirilmiştir. 16 katılımcıya ise posta yoluyla Q dizgisi 50X70 photoblok alanda, her bir Q-setin yer aldığ 1 ifadeler ve prosedür iletilmiştir. Bu katılımcılara prosedürlerin uygulanmasındeki destek araştırmacı tarafından Skype programı üzerinden sağlanmıştır.

\section{Q Seti}

Örgüt yönlü kararlar, etik ve sosyal sorumluluk uygulamaları örgüt içi aktivizm kişisel aktivizm, altı ve yedişerli ifade ile $Q$ seti oluşturulmuştur. 
Örgüt yönlü kararlar halkla ilişkilerin aktivist rolünden aksi bir yönü işaret etmektedir. Diğer yandan halkla ilişkilerin aktivist rolü, içinde bulunduğu toplumun bir üyesi sosyal olarak sorumlu ve etik uygulamaları gerçekleştirmesi ile de ilintilidir. Bu nedenle etik ve sosyal sorumluluk uygulamaları da bir faktör olarak $Q$ setinde yer almaktadır. Q setini oluşturan diğer iki faktör, örgüt içi aktivizm ve kişisel aktivizmdir. Şüphesiz halkla ilişkilerin aktivist rolünün gereği sadece örgütün dışındaki cılız seslere güç vermekten ibaret değildir, örgüt içindeki karşıt görüşlere ve fikir ayrilıklarına odaklanması da beklenmelidir. Uygulayıcıların kişisel olarak aktivizme bakış açıları da örgütsel rollerini etkileyebilir. Bu bağlam kişisel aktivizm faktörünün de $Q$ setinde yer almasının nedenidir. Aşağıdaki tablo 1 ve 2'de Q Dizgisi ve Set görülmektedir.

Tablo 1. Q Dizgisi

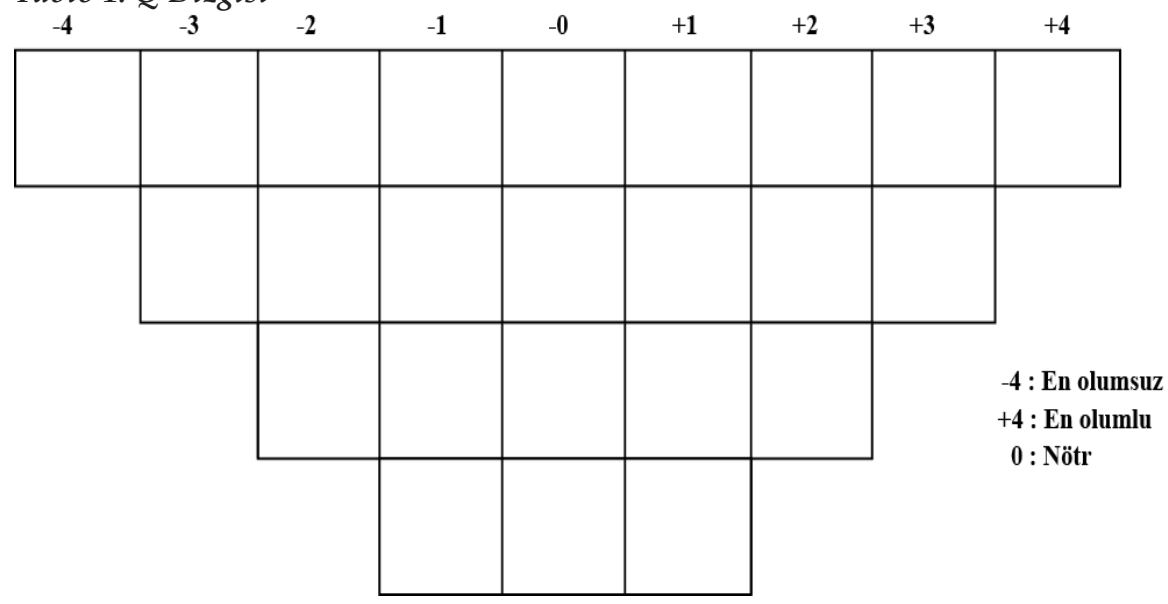


Tablo 2. Q Set

\section{İfadeler}

\begin{tabular}{|c|c|}
\hline Kişisel Aktivizm & $\begin{array}{l}\text {-Kendimi değişimlere açık biri olarak tanımlamam. } \\
\text {-Kişisel olarak aktivist örgütlerin aktif olarak (üyelik, ba- } \\
\text { ğışta bulunma, -etkinliklere katılma vb. yollar) destekçisi- } \\
\text { yim. } \\
\text {-Kişisel kaygılarım bazen gerçekleri ifade etmekte beni en- } \\
\text { geller. } \\
\text {-Sosyal sorumluluk uygulamalarını üretirken, hayata ba- } \\
\text { kış açım etkilidir. } \\
\text {-Örgütün sosyal politikalarındaki hatalı yönleri ifade et- } \\
\text { mek benim için önemlidir. } \\
\text {-Örgütün politikalarına karşı farklı fikirleri desteklemek- } \\
\text { ten çekinirim. } \\
\text {-İş yeri güvenliği, çevre politikaları gibi konulara dikkat } \\
\text { çekme ihtiyacı duyarım. }\end{array}$ \\
\hline Örgüt İçi Aktivizm & $\begin{array}{l}\text {-Örgütte sosyal politikalardan söz edilirken, farklı fikir- } \\
\text { lere odaklanmanın faydalı olduğunu düşünüyorum. } \\
\text {-Kamularla çatışma noktalarının tanımlanmasında halkla } \\
\text { ilişkiler uygulayıcılarının rolü vardır. } \\
\text {-Halkla ilişkilerin fikir birliği yerine fikir ayrılıklarına } \\
\text { odaklanması gerektiğine inanıyorum. } \\
\text {-Örgütün içinde toplumsal vicdan olma gibi bir rolüm ol- } \\
\text { duğunu düşünmüyorum. } \\
\text {-İş dünyası iştir, sosyal aktivizm değildir. } \\
\text {-Çalışanların örgüt politikalarına karşıt görüşlerinin dile } \\
\text { getirilmesini bunları örgüt politikalarını değiştirmek için } \\
\text { önemli görüyorum. }\end{array}$ \\
\hline $\begin{array}{l}\text { Etik ve Sosyal Sorumluluk Uy- } \\
\text { gulamaları }\end{array}$ & $\begin{array}{l}\text {-Toplumu geliştirmek için kaynakları aşırı kullanacak } \\
\text { yeni yollar aramaya gerek duymam. } \\
\text {-Örgüte kurumsal etik ile ilgili tavsiyeler veririm. } \\
\text {-Sosyal sorumluluk uygulamaları hakkında tavsiyelerim } \\
\text { dikkate alınır. } \\
\text {-Örgütün toplumun genelini ilgilendirmeyen çok spesifik } \\
\text { konularla ilgili sosyal bir uygulama geliştirmesini gerekli } \\
\text { görmüyorum. } \\
\text {-Örgütler sadece yasal düzenlemeler için değil sosyal me- } \\
\text { seleler için de aktif olarak kaynak ayırmalıdır. } \\
\text {-Örgüt ve toplum arasındaki ilişkileri etkileyebilecek güce } \\
\text { sahip değilim. }\end{array}$ \\
\hline
\end{tabular}




\begin{tabular}{ll}
\hline Örgüt Yönlü Kararlar & -Sosyal sorumluluk uygulamalarının örgütlere getirdiği \\
& rekabet avantajları gözardı edilemez. \\
& -Sosyal sorumluluk uygulamalarındaki kazançlar ve kar \\
& meseleleri genellikle birbirine karışmaz \\
& -Toplumsal meselelere ilişkin öncelikleri devlet yönetici- \\
& leri belirlemelidir, örgütler değil. \\
& -Yönetim toplantılarında masada yerim yoktur. \\
& -Örgütün sosyal rolünü ne kadar iyi yerine getirdiği karı \\
& ile doğru orantılıdır. \\
& -Toplumla ilişki kurarken örgütün politikalarını takip edi- \\
& yorum. \\
& -Kamuları örgütün kararlarına ikna etmede rol oynarım.
\end{tabular}

\section{Bulgular}

Q setindeki ifadelerde katılımcıların yüklendikleri faktörler ve değerlerin siralanması sonucu, Faktör 1, “Örgüt yönlü kararları", Faktör 2, "Etik ve Sosyal Sorumluluk Uygulamaları", Faktör 3 "Örgüt İçi Aktivizm” ve Faktör 4 "Kişisel Aktivizm" olarak tespit edilmiştir. Tanımlanan 4 faktöre 20 katılımcının en az ikisi yüklenmiştir. Tablo 3' de faktör yükleri açıklanmaktadır.

Katılımcıların Q seti +4 ile derecelendirdiği "Sosyal sorumluluk uygulamalarındaki kazançlar ve kar meseleleri genellikle birbirine karışmaz, "Toplumla ilişki kurarken örgütün politikalarını takip ediyorum”, "Kamuları örgütün kararlarına ikna etmede rol oynarım", "Sosyal sorumluluk uygulamaları hakkında tavsiyelerim dikkate alınır", "Örgütün toplumun genelini ilgilendirmeyen çok spesifik konularla ilgili sosyal bir uygulama geliştirmesini gerekli görmüyorum”, "Kamularla çatışma noktalarının tanımlanmasında halkla ilişkiler uygulayıcılarının rolü vardır”, “Örgütün sosyal politikalarındaki hatalı yönleri ifade etmek benim için önemlidir" ifadeler yer almaktadır. 
Tablo 3. Faktör Yükleri

\begin{tabular}{|c|c|c|c|c|}
\hline Katılımcı No & Faktör 1 & Faktör 2 & Faktör 3 & Faktör 4 \\
\hline 1 & 0.19 & $0.72 X$ & 0.54 & 0.35 \\
\hline 2 & $0.70 \mathrm{X}$ & 0.54 & 0.11 & -0.26 \\
\hline 3 & 0.21 & 0.43 & $0.79 X$ & 0.31 \\
\hline 4 & -0.19 & 0.58 & 0.67 & $0.71 X$ \\
\hline 5 & $0.78 \mathrm{X}$ & -0.45 & 0.34 & 0.48 \\
\hline 6 & $0.71 X$ & 0.40 & 0.21 & 0.18 \\
\hline 7 & $0.76 \mathrm{X}$ & 0.33 & 0.12 & 0.40 \\
\hline 8 & $0.70 \mathrm{X}$ & 0.20 & 0.47 & 0.45 \\
\hline 9 & $0.18 \mathrm{X}$ & $0.73 X$ & 0.17 & 0.53 \\
\hline 10 & 0.41 & $0.78 \mathrm{X}$ & 0.12 & 0.23 \\
\hline 11 & $0.79 \mathrm{X}$ & 0.39 & 0.27 & -0.16 \\
\hline 12 & 0.45 & 0.37 & 0.56 & $0.79 \mathrm{X}$ \\
\hline 13 & -0.29 & 0.40 & $0.70 \mathrm{X}$ & -0.12 \\
\hline 14 & $0.80 \mathrm{X}$ & 0.67 & 0.59 & 0.45 \\
\hline 15 & $0.77 \mathrm{X}$ & 0.51 & -0.41 & 0.48 \\
\hline 16 & 0.12 & $0.71 X$ & 0.59 & 0.19 \\
\hline 17 & -0.10 & 0.55 & $0.75 X$ & 0.62 \\
\hline 18 & 0.28 & 0.61 & $0.79 \mathrm{X}$ & 0.66 \\
\hline 19 & $0.80 \mathrm{X}$ & 0.72 & 0.40 & 0.53 \\
\hline 20 & 0.16 & $0.71 X$ & 0.54 & 0.11 \\
\hline
\end{tabular}

Diğer yandan $Q$ setindeki "Toplumsal meselelere ilişkin öncelikleri devlet yöneticileri belirlemelidir, örgütler değil", "Sosyal sorumluluk uygulamalarının örgütlere getirdiği rekabet avantajları gözardı edilemez", “Toplumu geliştirmek için kaynakları aşırı kullanacak yeni yollar aramaya gerek duymam", "Çalışanların örgüt politikalarına karşıt görüşlerinin dile getirilmesini bunları örgüt politikalarını değiştirmek için önemli görüyorum”, “Örgütün toplumsal vicdanı olma gibi bir rolüm olduğunu 
düşünmüyorum", "Sosyal sorumluluk uygulamalarını üretirken, hayata bakış açım etkilidir" ve "Kendimi değişimlere açık biri olarak tanımlamam" ifadeleri -4 ile derecelendirilmiştir. Bu ifadeler Tablo 4'de gösterilmektedir.

\section{Tablo 4. Faktörler ve +4 ile -4 Olarak Derecelendirilen If fadeler}

\begin{tabular}{|c|c|c|}
\hline Faktörler & $\begin{array}{l}\text { +4 olarak derecelendirilen ifade- } \\
\text { ler }\end{array}$ & -4 olarak derecelendirilen ifadeler \\
\hline \multirow{3}{*}{$\begin{array}{l}\text { Faktör } 1 \\
\text { Örgüt yönlü kararlar }\end{array}$} & $\begin{array}{l}\text { Sosyal sorumluluk uygulamala- } \\
\text { rındaki kazançlar ve kar mesele- } \\
\text { leri genellikle birbirine karışmaz }\end{array}$ & $\begin{array}{l}\text { Toplumsal meselelere ilişkin öncelik- } \\
\text { leri devlet yöneticileri belirlemelidir, } \\
\text { örgütler değil. }\end{array}$ \\
\hline & $\begin{array}{l}\text { Toplumla ilişki kurarken örgütün } \\
\text { politikalarını takip ediyorum. }\end{array}$ & \multirow[t]{2}{*}{$\begin{array}{l}\text { Sosyal sorumluluk uygulamalarının } \\
\text { örgütlere getirdiği rekabet avantajları } \\
\text { gözardı edilemez. }\end{array}$} \\
\hline & $\begin{array}{l}\text { Kamuları örgütün kararlarına } \\
\text { ikna etmede rol oynarım. }\end{array}$ & \\
\hline \multirow[b]{2}{*}{$\begin{array}{l}\text { Faktör } 2 \\
\text { Etik ve Sosyal Sorum- } \\
\text { luluk Uygulamalar }\end{array}$} & $\begin{array}{l}\text { Sosyal sorumluluk uygulamaları } \\
\text { hakkında tavsiyelerim dikkate } \\
\text { alınır. }\end{array}$ & \multirow[t]{2}{*}{$\begin{array}{l}\text { Toplumu geliştirmek için kaynakları } \\
\text { aşırı kullanacak yeni yollar aramaya } \\
\text { gerek duymam. }\end{array}$} \\
\hline & $\begin{array}{l}\text { Örgütün toplumun genelini ilgi- } \\
\text { lendirmeyen çok spesifik konu- } \\
\text { larla ilgili sosyal bir uygulama } \\
\text { geliştirmesini gerekli görmüyo- } \\
\text { rum. }\end{array}$ & \\
\hline \multirow[t]{2}{*}{$\begin{array}{l}\text { Faktör } 3 \\
\text { Örgüt içi aktivizm }\end{array}$} & \multirow[t]{2}{*}{$\begin{array}{l}\text { Kamularla çatışma noktalarının } \\
\text { tanımlanmasında halkla ilişkiler } \\
\text { uygulayıcılarının rolü vardır. }\end{array}$} & $\begin{array}{l}\text { Örgütün içinde toplumsal vicdan } \\
\text { olma gibi bir rolüm olduğunu düşün- } \\
\text { müyorum. }\end{array}$ \\
\hline & & $\begin{array}{l}\text { Çalışanların örgüt politikalarına kar- } \\
\text { şıt görüşlerinin dile getirilmesini bun- } \\
\text { ları örgüt politikalarını değiştirmek } \\
\text { için önemli görüyorum. }\end{array}$ \\
\hline \multirow[t]{2}{*}{$\begin{array}{l}\text { Faktör } 4 \\
\text { Kişisel aktivizm }\end{array}$} & \multirow[t]{2}{*}{$\begin{array}{l}\text { Örgütün sosyal politikalarındaki } \\
\text { hatalı yönleri ifade etmek benim } \\
\text { için önemlidir. }\end{array}$} & $\begin{array}{l}\text { Sosyal sorumluluk uygulamalarını } \\
\text { üretirken, hayata bakış açım etkilidir. }\end{array}$ \\
\hline & & $\begin{array}{l}\text { Kendimi değişimlere açık biri olarak } \\
\text { tanımlamam. }\end{array}$ \\
\hline
\end{tabular}

*Dağılımda, en az 5 katılımoının paylaştı̆̆ı ifadeler açıklanmıştır. 
+4 ile -4 ile derecelendirilen ifadeler, yalın biçimde uygulayıcıların örgütleri, kurumsal birer vatandaş olarak gördüklerini göstermektedir. Ancak örgütün kararlarını meşrulaştırmaya da eğilimlidirler. Örgüt yönlü asimetrik eğilimlerine rağmen, şaşırtıcı bir biçimde uygulayıcılar sosyal sorumluluğun örgütlere rekabet avantajı getirdiğine inanmamaktadırlar. Dahası, sosyal sorumluluk uygulamalarındaki kazançlar ve kar meseleleri genellikle birbirine karışmaz. Sosyal sorumluluğa yönelik bu bakış, halkla ilişkilerin aktivist rolünü işaret edebilir. Zira sosyal sorumluluğa pazarda rekabet üstünlüğü sağlayacak bir uygulama olarak bakmamak, halkla ilişkiler örgüt tarafına çok daha yakın dursa dahi, uygulayıcıların toplumsal bir rolü olduğunu işaret eden ilk anlamlı bulgu olarak okunabilir. Diğer yandan ortaklanmış bir algı olarak ifade edilemeyecek olsa da, 20 katılımcinın 4'ünün, Faktör 1'de yer alan "Sosyal sorumluluk uygulamalarının örgütlere getirdiği rekabet avantajları gözardı edilemez" ifadesini -1 ile -4 aralığında derecelendirmesi de halkla ilişkilerin toplumsal rolüne ilişkin bir bulguyu ifade edebileceği için değerlidir.

Faktör 1, örgüt yönlü kararlar görüşünü paylaşan bakış açısıdır. Bu faktörde "Toplumla ilişki kurarken örgütün politikalarını takip ediyorum" ve "Kamuları örgütün kararlarına ikna etmede rol oynarım" ifadeleri +4 ile derecelendirilmiştir. Bu, uygulayıcının örgütün sesi olarak konumlandığı net biçimde açığa çıkarmaktadır. Faktör 2 "Etik ve Sosyal Sorumluluk Uygulamalar"1 açıklamaktadır. Uygulayıcıların buradaki ifadelere verdiği derecelerle, toplumsal olana ilgi bir kez daha görünür olmaktadır. Zira uygulayıcılar, toplumu geliştirmek için kaynakları aşırı kullanacak yeni yollar aramaya gerek duyar ve etik kaygıları dillendirir. ("Örgüte kurumsal etik ile ilgili tavsiyeler veririm" ifadesi +1 ile +4 arasında derecelendirilmiştir) Lakin uygulayıcıların örgütün toplumun genelini ilgilendirmeyen çok spesifik konularla ilgili sosyal bir uygulama geliştirmesini gerekli görmemesi, azınlık fikirleri ve halkla ilişkilerin farklı seslere yansıtmadaki gücüne ilişkin şüphe duymaya neden olmaktadır. Bu şüpheyi arttıracak başka bir bulgu da uygulayıcıların, çalışanların örgüt politikalarına karşıt görüşlerinin dile getirilmesini, örgüt politikalarını değiştirmek için önemli görmemesidir. "örgüt içi aktivizm"i açıklayan ifadelerden biri olarak bu ifade +4 ile derecelendirmiştir. Halkla ilişkilerin farklılıkları tanımlamaya yönelik bakışı bu bulguda görünür olmaktadır. Diğer yandan halkla iliş- 
kiler uygulayıcıları tensörlerin tanımlanmasında kendilerine rol biçmektedir. Ayrıca, toplumsal olana eğilimi gösterecek başka bir bulguya daha ulaşılmıştır. Zira uygulayıcılar örgütün toplumsal vicdanı olma gibi bir rolleri olduğunu düşünmektedir. Örgüt içi aktivizm boyutunda az sayıda ifadede ortaklık bulunmaktadır.

Faktör 4 "kişisel aktivizm"i açıklamaktadır. Halkla ilişkiler uygulayıcılarının fikirlerindeki en önemli ortaklık, uygulayıcıların kendilerini değişimlere açık olarak tanımlamalarıdır (20 katılımcının 16'sında +4 ile derecelendirilmiştir). Ancak şaşırtıcı biçimde uygulayııılar sosyal sorumluluk uygulamalarını üretirken, hayata bakış açılarını yansıtmamaktadırlar. Diğer yanda etik kaygılar uygulayıcılar için değerlidir ("Örgütün sosyal politikalarındaki hatalı yönleri ifade etmek benim için önemlidir" ifadesi 20 katılımonın 17 'sinde +4 ile derecelendirilmiştir). Uygulayıcılar -2 ile -4 arasında bir derece ile "kişisel olarak aktivist örgütlerin aktif olarak (üyelik, bağışta bulunma, etkinliklere katılma vb. yollar) destekçisi" olmadıklarını ifade etmektedir (Katılımcların 9' $\mathrm{u},+1$ ile +4 arasında derecelendirmiştir). Diğer yandan nötr (0) derecesi en çok bu boyutta saptanmıştır. Öyle ki, örgütün politikalarına karşı farklı fikirleri desteklemekten çekinirim ifadesi, 20 katılımcının 7'sinin nötr (0) olarak derecelendirdikleri bir ifadedir. Diğer yanda, "İş dünyası iştir, sosyal aktivizm değildir" ifadesi de nötr sonuçların ağırlıklı olduğu ifadelerdendir (Katılımcının 6'sı ifadeyi 0 ile derecelendirmiştir). "Örgütler sadece yasal düzenlemeler için değil sosyal meseleler için de aktif olarak kaynak ayırmalıdır" ifadesi + değerlerler ile derecelendirilmiştir. Bu bulgu, toplumsal meselelere eğilimi açıklayan diğer bulgularla örtüşmektedir. Uygulayıcıların yönetim toplantılarındaki yeri ve bu yerde ne yaptıkları da aktivist rollerine ilişkin ipuçları vermektedir. Öyle ki, uygulayıcılar yönetim toplantılarında örgütsel makro politikalar yerine, iş yeri güvenliği, çevre politikaları gibi konularla yer almaktadır ("İş yeri güvenliği, çevre politikaları gibi konulara dikkat çekme ihtiyacı duyarım" ifadesi -3 ile 0 arasında derecelendirilmiştir. "Örgütün sosyal politikalarındaki hatalı yönleri ifade etmek benim için önemlidir" ifadesi de fikir birliği saptanamamış ifadelerdendir (Katılımcıların 7'si - değerler ile 6'sı + değerler ile derecelendirmiştir). 


\section{Sonuç}

$\mathrm{Bu}$ araştırma, halkla ilişkilerin dar tanımlanmış bir örgütsel işlevden ziyade toplum üzerinde geniş kapsamlı etkileri olan bir disiplin olarak, toplumsal, kültürel ve politik bağlamda anlaşılması ve incelenmesi gerektiğinden (Holthauzen, 2000) hareket almıştır. Araştırmanın ardalanındaki postmodern yaklaşımın temel vurguları, halkla ilişkilerin rolüne ilişkin alternatif bir anlayışını açıklayacak farklı bir bakış açısı sağlamaktadır. Bu bağlama yaslananarak araştırmada halkla ilişkilerin, planlayan, denetleyen, ölçen ve yeniden düzenleyen yönetimsel rolü yerine aktivist rolüne ilişkin arayış, örgüt yönlü kararlar, etik ve sosyal sorumluluk uygulamaları, örgüt içi aktivizm ve kişisel aktivizm boyutlarıyla tartışılmıştır. Dört boyutun göstergeleri halkla ilişkiler uygulayıcılarının, örgütün sosyal vicdanı ve bir değişim aracı ya da toplumsal dönüşümün temsilcisi olarak ne yaptığını açıklamaya çabasındadır.

Örgüt yönlü kararlara eğilim, halkla ilişkiler uygulayıcılarının aktivist rolünün varlığına ilişkin şüpheli bir bakışa neden olmuştur. Zira uygulayıcıların toplumla ilişki kurarken örgütün politikalarını takip etmesi ve kamuları örgütün kararlarına ikna etmede rolleri olduğuna inanmaları ile değişim arayışı ve zayıf sesleri güçlendirme ile aynı yerde işleyemez. Bu anlamda bu araştırmanın sözünü edebileceği ilk önemli sonuç, örgüt yönlü kararların halkla ilişkilerin rolünü açıklamada baskın oluşudur. Görünen o ki, muhafazakâr bir rolle (Grunig ve White, 1992) uygulayıcılar, işlerini asimetrik olarak, ekonomik ve politik olarak güçlü olanın çıkarları ve ayrıcalıkları olarak savunmaktadırlar. Kişisel kaygılarının bazen gerçekleri ifade etmeye engel olması da bu nedene bağlanabilir. Lakin aktivist rolün varlığına ilişkin bazı zayıf kanıtlardan söz etmek mümkündür. Bu kanıtlar en çok halkla ilişkiler uygulayıcılarının toplumsal meselelere bakışında bulunabilir. Halkla ilişkiler uygulayıcılarının örgütün toplumsal vicdanı olma rolleri olduğunu düşünmeleri, dahası sosyal sorumluluğu kâr amacının dışında tutmaları bunu işaret etmiştir. Halkla ilişkilerin Molleda ve Ferguson'ın (2004) açıkladığı biçimiyle sosyal bir rolü olduğu açıktır. Yönetime verdikleri sosyal sorumluluk ve etik tavsiyeler de uygulayıcıların bu rolü yerine getirmedeki motivasyonlarını ifade etmektedir. 
Uygulayıcıların, aktivist rolün izleklerinden biri olarak kamularla çatışma noktalarının tanımlanmasında da bir rolleri vardır. Çatışma noktalarını tanımlamadaki bu rol, örgüt yönlü kararların baskın oluşu da düşünüldüğünde değişim yaratacak tensörlerin tanımlanmasını değil, daha çok kriz zamanlarının eylemlerini düşündürmektedir. Bu araştırmanın bulguları ile örtüşecek biçimde, Mykkänen ve Vos da (2015) yönetim masasında yeri olanların da halkla ilişkilerden genel politikalara ilişkin tavsiyeler yerine kurumsal etik, kriz iletişimi, sosyal sorumluluk gibi konularda tavsiyeler beklediklerine ilişkin kanıtlar sunmuştur. Danışmanlık rolünde halkla ilişkiler kendi uzmanlığındaki bilgileri aktarmaktadır. Aslında baskın koalisyonun bir parçası olma, uygulayıcının iktidar yapısına rızasını gösterir ve şüphesiz eylemci rolünün zorlaşmasının nedeni olarak da gösterilebilir.

Halkla ilişkiler uygulayıcıları farklı sesleri tanımlamaya ve fikir ayrılıklarına odaklanmaya eğilimli olmamaları aktivist rolün varlığına tezat bir işarettir. Bu sonuç beraberinde bir soruyu da getirmektedir; örgütün toplumsal vicdanı olarak görünen halkla ilişkileri neden örgütün politikalarına karşı farklı fikirleri desteklemekten çekinmektedir? Sorunun yanıtı araştırmanın kişisel aktivizm boyutundaki bulgularla ilişkili olabilir. Holthauzen ve Voto (2002) kişisel olarak güçlü, benlik hissi yüksek olan uygulayıcıların, egemen örgütsel güç yapılarına direnmesi ve iktidar statüsünü kabul eden uygulayıcılardan çok örgütsel aktivistler olarak davranması daha olası olduğunu ifade etmektedir. Yine Foucault'un (1988, s. 71) biyogüç kavramına atıfla yazarlar biyo-güç olmaksızın, politik gücün bireyi etkilediğine ve itaat ve uygunluğu indüklediğine inanmaktadır Kişisel olarak aktivist örgütleri aktif olarak (üyelik, bağışta bulunma, etkinliklere katılma vb. yollar) desteklemeyen uygulayıcıların örgüt içinde aktivist bir rolü üstlenmelerini beklemek doğası gereği tartışmalı olabilir. Zira Simon vd. (1988) aktivist bir davranış için kolektif, sosyal ve ödül motivasyonlardan birine ya da birkaçına sahip olmak gerektiğinden söz etmektedir. Uygulayıcıların kişisel dünyalarında bu motivasyonların eksikliği, örgütte de aktivist bir rol üstlenememesinin nedeni olabilir. Ayrıca uygulayıcılar hayata bakış açılarını sosyal sorumluluk uygulamalarına da yansıtmamaktadır. Halkla ilişkiler etiğinin ironisi de, kişisel değerlerin tutarlı bir şekilde uygulanamamasıdır (Grunig, 2000, s. 29). 
Nihayetinde Lyotard'ın (1990) sunulamayana tanıklık etme ve farklılıkları etkin kılma fikri, halkla ilisskiler alanı için şimdilik fazlaca iddialı gibi durmaktadır. Yine de zayıf da olsa kanıtların varlığı aktivist bir halkla ilişkiler için başlangıç noktası olarak sayılabilir. Zira halkla ilişkiler, ekonomik, politik, sosyal ve kültürel yapının görülmemiş bir hızla değişimine yanıt olarak farklılıkları anlamanın, bu farklılıklara odaklanarak değişime kaynak olmanın peşine düşmelidir. Diğer yandan halkla ilişkilerin sosyal sermayeye nasıl katkı sağlayacağı ve bu yolla aktivist rolü nasıl birleştirebileceğini araştırmak halkla ilişkilerin postmodernizim ardalanında yeni bir bakış açısı sağlayabilir. Son olarak halkla ilişkileri aktivist rolle tanımlayabilmek için kişisel aktivizmin değeri daha çok ilgiyi hak etmektedir. 


\title{
EXTENDED ABSTRACT
}

\section{A Search For The Role of Public Relations Activist in The Background of Postmodernizim}

\author{
Aslı İcil Tuncer \\ Aydin Adnan Menderes University
}

Postmodernism's multiculturalism and the discovery of numerous global societies can be explained as one of the reasons. It is the communicative force in the society that serves to reproduce and / or transform. Therefore, public relations should be valued as a profession which can ensure the reproduction of emancipation and transformation. The postmodern view is to open another front of public relations, rather than an ongoing modernist approach. This facade can contribute to understanding the effects of public relations on society rather than a narrowly defined organizational function in a wider social, cultural and political context (Holtzhausen, 2000). This study in the search for the activist role of public relations in the postmodern world seeks to trace public relations as an agent of change by discovering differences and strengthening rickety sounds. There can also be a normative expectation that public relations can build a new meaning by keeping itself out of organizational values. However, as Foucault (1988, p.118), who focused on the individual as the conscious participant who had the power to resist macro power, there was the possibility of resistance when there is a power relationship.

The public relations field has been criticized for many years due to weak ethical and suspicious practices. Terms such as the loop doctor and consent engineer have become part of the arsenal of those who challenge the ethics and reliability of public relations practitioners (Houlthauzen and Voto, 2002). A postmodern look can lead to the creation and transformation of social values, to serve as the conscience of the organization and to give voice to non-rulers. Holtzhausen (2000) argues that public relations practice can be more ethical if organizations act as activist roles in public relations, while public relations can contribute to democracy and freedom 
in societies by working in, not by destroying, building, or liberating (p.110). This study, which considers postmodernism, seeks to find evidence of the presence of the activist role of public relations. Ultimately, he argues that looking at practitioner behavior with a postmodern lens would provide a different understanding of meso- and macro-level public relations. Working with these arguments asks: Does public relations practitioners play an activist role in organizations?

In this study, evidence of activist roles of public relations practitioners was searched by $Q$ method. $Q$ is the name of the method in which a large number of respondents make a ranking that minimizes themselves from within the judiciary. The method focuses on the subjectivity of the individual (personal perspective, attitudes and beliefs) (Brown, 1986). The method has three components: the development of sets of descriptors to which points will be scored; points and the analysis of data. (Waters and Deane, 1985, p. 52). Q researchers are looking for a pattern between variables for each subject. The perspectives of the participants are modeled by systematic sequences called Q-sampling (McKeown and Thomas, 1988). In the Q-string, between the 4 negative end and +4 positive end, the compulsory normal distribution structure was used.

This research has taken action because public relations has to be understood and examined in a social, cultural and political context as a discipline which has wide influence on society rather than a narrowly defined organizational function (Holthauzen, 2000). The main emphasis of the postmodern approach behind the study provides a different perspective to explain an alternative understanding of the role of public relations. In this context, the search for the role of activists in the role of the public relations in the research, planning, controlling, measuring and reorganizing the role of the activist, organization-oriented decisions, ethical and social responsibility practices, organizational activism and personal activism dimensions are discussed. Indicators of four dimensions attempt to explain what public relations practitioners do as the social conscience of the organization and as a representative of change or social transformation.

Practitioners have a role in defining the points of conflict with the as one of the paths of the activist role. This role in defining the points of conflict is not the definition of tensors that will create change considering the dominance of organization-oriented decisions, but rather the actions of 
the times of crisis. In line with the findings of this research, Mykkänen and Vos (2015) provided evidence that those who were on the executive board had expected recommendations on issues such as corporate ethics, crisis communication and social responsibility rather than public policy recommendations. Public relations in the role of consultancy transfers information in their expertise. In fact, being part of the dominant coalition demonstrates the consent of the practitioner to the structure of power and, of course, it can be seen as the reason for the difficult role of the activist.

Public relations practitioners are not inclined to identify different voices and to focus on disagreements, a contrast to the existence of an activist role. This result brings with it a question; Why do public relations appear to be the social conscience of the organization to support different ideas against the policies of the organization? The answer to the question may be related to the findings of the personal activism dimension of the study. Holthauzen and Voto (2002) suggest that practitioners with strong personal, self-esteem are more likely to resist the dominant organizational structures and act as organizational activists rather than practitioners who accept the status of power. Again, referring to the bio-power concept of Foucault (1988, p. 71), the authors believe that without bio-power, political power influences the individual and induces obedience and appropriateness. Waiting for non-supporters to assume an activist role within the organization may be inherently controversial. Because Simon et al. (1988) speaks of the need to have one or more of collective, social and reward motivations for an activist behavior. The lack of these motivations in the personal world of practitioners may be the reason why they cannot play an activist role in the organization. In addition, practitioners do not reflect their perspective on life in social responsibility practices. The irony of ethics of public relations is the inability to apply personal values consistently (Grunig, 2000, p. 29).

As a result, Lyotard's (1990) idea of witnessing the inaccessible and making the differences effective seems to be too ambitious for public relations. Nevertheless, the presence of evidence may be considered as a starting point for an activist public relation. Because public relations, economic, political, social and cultural structure in response to an unprecedented rate of change in understanding differences, focusing on these differences should be the source of change. On the other hand, researching 
how public relations will contribute to social capital and in this way how the activist role can be combined may provide a new perspective in the postmodernism of public relations. Finally, the value of personal activism deserves more attention in order to define public relations with the activist role.

\section{Kaynakça / References}

Broom, G. M., ve Smith, G. D. (1979). Testing the practitioner's impact on clients. Public Relations Review, 5(3), 47-59.

Broom, G. M. (1982). A comparison of sex roles in public relations. Public Relations Review, 8(3), 17-22.

Brown, S.R. (1986). Q technique and method: Principles and procedures. In William D. Berry ve Michael S.,Lewis-Beck (Eds.), “New tools for social scientists: Advances and applications in research methods". Beverly Hills, CA: Sage.

Bourdieu, P., (1986). The forms of capital. In J. G. Richardson (Eds), Handbook of Theory and Research for the Sociology of Education, New York: Greenwood Press.

Bowen, S. A. (2007). The extent of ethics. In E. L. Toth (Eds.), The future of excellence in public relations and communication management. Mahwah, NJ: Lawrence Erlbaum.

Coombs, W. T., Ve Holladay, S. J. (2007). It's not just PR: Public relations in society. Malden, MA: Blackwell Publishing.

Curtin, P.A. ve Gaither T.K. (2005). Privileging identity, difference, and power: The circuit of culture as a basis for public relations theory, Journal of Public Relations Research, 17(2), 91-115.

Cutlip, S.M., Center A.H. ve Broom, G.M. (2000). Effective public relations. 8th Edition, Prentice Hall, Upper Saddle River, NJ.

Deetz, S. (2001). Conceptual foundations. In F. M. Jablin ve L. L. Putnam (Eds.), New handbook of organizational communication: Advances in theory, research, and methods, Thousand Oaks, CA: Sage.

Dhanesh, G.S, (2013) Building communities: The postmodern CSR practitioner as a dialectical activist-agent in India, Public Relations Review, 39, p. 398-402. 
Dozier, D. M. (1984). Program evaluation and the roles of practitioners. Public Relations Review, 10(2), 13-21.

Dozier, D. M., Grunig, L. A., ve Grunig, J. E. (1995). Manager's guide to excellence in public relations and communication management. Mahwah, NJ: Erlbaum

Dozier, D. M. (1984). Program evaluation and the roles of practitioners. Public Relations Review, 10(2), 13-21.

Dozier, D. M., ve Broom, G. M. (1995). Evolution of the manager role in public relations practice. Journal of Public Relations Research, 7(1), 3-26.

Edwards, L. ve Hodges, C. (2011). Introduction Implacations of a (radical) Socio-Cultural turn İn public relations scholarship. In L.Edwards ve C.E.M. Hodges (Ed.) Public relations, society ve culture. London:Routledge.

Freeman, R.E., (1983). Stockholders and stakeholders: a new perspective on corporate governance, California Management Review, 25 (3), 88-106.

Foucault, M. (1988). Power and sex. In L. D. Kritzman (Ed.), Michel Foucault: Politics, philosophy, culture. New York: Routledge.

Grunig, J.E. ve Hunt, T. (1984). Managing public relations, Rinehart and Winston, New York.

Grunig, J.E., ve Grunig L.A. (1989). Toward a theory of public relations behavior in organizations: review of a program of research, Public Relations Research Annual, 1, p.27-66.

Grunig J.E (2000). Collectivism, Collaboration, and Societal Corporatism as Core Professional Values in Public Relations, Journal of Public Relations Research, (12)1, 23-48.

Grunig, J. E., ve White, J. (1992). The effect of worldview on public relations theory and practice. In J. E. Grunig (Eds), Excellence in Public Relations and Communication Management, Hillsdale, NJ, Lawrence Erlbaum Associates.

Habermas J. (1997). Bilgi ve insansal ilgiler. (C.A.Kanat Trans) İstanbul, Turkey: Küyerel Yayınları.

Han, J. (2002). A typological study on the PR practitioners' perception toward their job roles and functions. Korean J. Mass Commun. Q. 46, $112-249$. 
Holtzhausen D.R., ve Voto, R. (2002). Resistance from the margins: The postmodern public relations practitioner as organizational activist. Journal of Public Relations Research, 14(1), 57-84.

Holtzhausen, D. (2011). The need for a postmodern turn in global public relations. In N. Bardhan, ve C. K. Weaver (Eds.), Public relations in global cultural contexts. Multi-paradigmatic perspectives, New York: Routledge.

Holtzhausen, D. R. (2000). Postmodern values in public relations. Journal

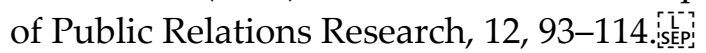

Ihlen, O. (2005). The power of social capital: Adapting Bourdieu to the study of public relations. Public Relations Review, 31(4), 492-496.

Ihlen, O. (2007). Building on Bourdieu: A sociological grasp of public relations. Public Relations Review, 33, 269-274.

Kaiser, H. F. (1958). The varimax criterion for analytic rotation in factor analysis. Psychometrika, 23(3), 187-200.

Kennedy, A.K. ve Sommerfeldt, E.J (2015). A postmodern turn for social media research: theory and research directions for public relations scholarship. Atlantic Journal of Communication, 23(1), 31-45.

Kim, S.Y., ve Kim, Y. (2009). The Influence of cultural values on perceptions of corporate social responsibility: Application of Hofstede's dimensions to Korean public relations practitioners. Journal of Business Ethics, 91, 485-500.

Kruckeberg, D., ve Starck, K. (1988). Public Relations and Community: A Reconstructed Theory. New York: Praeger.

Kruckeberg, D., ve Vujnovic, M. (2006). Toward an "organic model" of public relations in public diplomacy. Paper presented at the 9th International Public Relations Research Conference, Miami, FL.

Kruckeberg, D. (2006). An 'organic model' of public relations: the role of public relations for governments, civil society organizations (CSOs) and corporations in developing and guiding social and cultural policy to build and maintain community in 21st-century civil society. Keynote speech given at the international conference $\mathrm{Mu}-$ nicipal Social Policy and Publics: Realities and Perspectives, UlanUde, Buryatia, Russia. 
Kruckeberg, D., ve Vujnovic, M. (2010). The death of the concept of publics (plural) in 21st century public relations, International Journal of Strategic Communication, 4(2), 117-125.

Laclau, E., ve Mouffe, C. (1985). Hegemony and socialist strategy: Toward a radical democratic politics. London: Verso Books.

Laclau, E. (1988). Politics and the limits of modernity. In Universal abandon A. Ross (Eds.), Minneapolis: University of Minnesota Press.

Lyotard, J.F. (1984). The postmodern condition: A report on knowledge. Minneapolis, MN: University of Minnesota Press.

Lyotard, J.F. (1990). Postmodern Durum. (A.Çiğdem Trans) İstanbul, Turkey: Arı Yayınları.

Lyotard J.F. (1991). The inhuman: Reflections on time. (G. Bennington ve R. Bowlby. trans.) Polity Press, Cambridge.

McKeown, B., ve Thomas, D. (1988). Q Methodology. Sage Publications, Beverly Hills.

Molleda, J.-C., ve Ferguson, M. A. (2004). Public relations roles in Brazil: Hierarchy eclipses gender differences. Journal of Public Relations Research, 16, 327-351.

Motion, J., ve Leitch, J. (1996). A discursive perspective from New Zealand: Another world view. Public Relations Review, 22(3), 297-309.

Mykkänen, M., ve Vos, M. (2015). The contribution of public relations to organizational decision making: Insights from the literature. Public Relations Journal, 9(2), 1-17.

Pavlik, J.V. (1987). Public relations: What research tells us. Newbury Park, CA: Sage.

Pearson, R., (1992). Perspectives on public relations history. In E.L. Toth, R.L.

Heath (Eds.), Rhetorical and Critical Approaches to Public Relations, Lawrence Erlbaum, Hillsdale, NJ.

Putnam, R. D. (2000). Bowling alone: The Collapse and Revival of American Community. NY: Simon and Schuster.

Roper, J. (2005). Symmetrical communication: Excellent public relations or a strategy for hegemony? Journal of Public Relations Research, 17(1), 69-86. 
Sha, B.L. (2011). Practice Analysis: Professional competencies and work categories in public relations today Public Relations Review, 3, 187196.

Simon B., Loewy M., Stürmer S., Weber U., Freytag P., Habig C., Kampmeier, C., P. Spahlinger. (1998). Collective identification and social movement participation, Journal of Personality and Social Psychology, 74, 646-658.

Sommerfeldt, E. J., ve Taylor, M. (2011). A social capital approach to improving public relations' efficacy: Diagnosing internal constraints on external communication. Public Relations Review, 37(3), 197-206.

Tuncer, A. (2015). Kurumsal yönetim ilkeleri ile mükemmel halkla iliş,kiler bağ üzerine bir analiz, İletiş̧im Kuram Ve Araştırma Dergisi, 40, 215.

Tuncer, M. U. (2018). Historical dimension of international public relations In M.U. Tuncer (Eds.), International Public Relations, Berlin:Peter Lang $\mathrm{GmbH}$

Verhoeven P., Zerfass, A., Vercíc D., Tench, R., ve Moreno, A. (2018). Public relations and the rise of hypermodern values: Exploring the profession in Europe, Public Relations Review, 44, 471-480.

Vujnovic, M. (2005). The public relations practitioner as ombudsman-A reconstructed model. Paper presented at the 8th International Public Relations Research Conference, Miami, FL.

Yang, A., ve Taylor, M. (2013). The relationship between the professionalization of public relations, societal social capital, and democracy: Evidence from a cross-national study. Public Relations Review, 39(4), 257-270.

Waters, E., ve Deane, K. (1985). Defining and assessing individual differences in attachment relationships: Q-methodology and the organization of behavior in infancy and early childhood. In I. Bretherton ve E. Waters (Eds.), Growing points of attachment theory and research Monographs of the Society for Research in the Child Development, $50(1-2)$.

Wehmeier, S. (2006). Dancers in the dark: The myth of rationality in public relations. Public Relations Review, 32(3), 213-220. 
Zhang, W. ve Abitbol, A. (2016). The role of public relations in social capital. Online Journal of Communication and Media Technologies. 6(3), 211-233.

Schmolck, P. (2014). PQMethod 2.35. Alıntı tarihi: 10.07.2018 http://schmolck.userweb.mwn.de/qmethod/

\section{Kaynakça Bilgisi / Citation Information}

İcil-Tuncer, A. (2019). Postmodernizm ardalanında halkla ilişkilerin aktivist rolüne yönelik bir arayış. OPUS-Uluslararası Toplum Araştırmaları Dergisi, 10(17), 973-1001. DOI: 10.26466/opus.522169 